\title{
The European Statements of Hospital Pharmacy: the perspective of EAHP members
}

\author{
David Preece
}

\section{Correspondence to}

David Preece, Department of

Policy and Advocacy, The European Association of Hospital Pharmacists, Rue Abbé Cuypers, 3, Brussels 1040, Belgium;

David.preece@eahp.eu

Received 8 August 2014 Accepted 11 August 2014

\section{INTRODUCTION}

An accompanying article by Lee Vermeulen (see page 262) describes how the Basel Statements (2008) were planned, discussed and finally agreed on at a global conference. These statements laid out the future of hospital pharmacy. For all pharmacists it is important to know where the profession is heading and what we are striving to achieve, and importantly, at every stage to remember the reason why. The main role of hospital pharmacists is to improve the safety of patients by using their medicines correctly, and that is clear from the very first European statement:

The overarching goal of the hospital pharmacy service is to optimise patient outcomes through working collaboratively within multidisciplinary teams in order to achieve the responsible use of medicines across all settings.

It is hoped that this and other statements will result in hospital pharmacists having the tools they need to improve services, encourage collaboration and improve patient safety. The distinctive involvement of hospital pharmacists from across the EAHP membership, allied healthcare professionals and patient representatives was fundamental in reaching this juncture for hospital pharmacy practice in Europe.

In order to share their views on how these statements will influence hospital pharmacy practice across Europe, EAHP member representatives provided feedback after the Summit was over.

\section{ASPIRATION OF EUROPEAN HOSPITAL PHARMACISTS}

Feedback from EAHP members sought after the Summit showed that there was agreement that the statements reflect the aspiration of European hospital pharmacists to improve patient care.

I am fully convinced that the EAHP Statements reflect the aspiration of European hospital pharmacists. (Nenad Miljkovic, The Pharmaceutical Association of Serbia, Hospital Pharmacy Section)

They are the minimum that should be delivered for safe and effective care. (David Miller, The Guild of Healthcare Pharmacists, UK)

I'm certain that the statements reflect the aspiration. (Franci Tratar, Slovenian Pharmaceutical Society, Section of Slovenian Hospital Pharmacists)

[The statements only partially reflect the input of hospital pharmacists] because not every modification made during [the] session appeared in the final published statements. (Sylvain Rodenbach and Julie Schelinsky, The Luxembourg Association of Hospital Pharmacists)

\section{THE DELPHI PROCESS}

Richard Price's article (see page 276) describes the involvement of other professions and patients in the debate on hospital pharmacy topics. Involvement in the Delphi process was also interesting for EAHP members. A key process used in the Summit proceedings was an online discussion, which was anonymous and allowed open dialogue in advance of the actual conference. At the Summit itself, the views of all stakeholders, including other professions and patients, could be shared and a consensus found. This was an interesting project for me to help set up and coordinate, but what did EAHP members think about it?

It was [a] well chosen method for [finding out] opinions. (Marek Lžičař, Czech Association of Hospital Pharmacists)

The process was straightforward and encouraged some lively debates. The inherent anonymity is an added plus for freely articulated opinions. (András Süle, Hungarian Society of Hospital Pharmacists)

I think that it was a very good idea to involve all stakeholders in this process. (Franci Tratar, Slovenian Pharmaceutical Society, Section of Slovenian Hospital Pharmacists)

The Delphi process is good for different opinions. (Miroslav Kota, Croatian Pharmaceutical Society)

I thought it was an excellent way to determine the opinions and views of so many people. (EAHP Member)

This was a major leap forward. The Basel Statements were written from inside by pharmacists, but now we have much broader support from (a) patients and (b) our professional colleagues. This is exactly what others have done too: seek support from patient organisations. (Arnold G. Vulto, Dutch Association of Hospital Pharmacists)

The process is great, just a little bit slow in starting up the discussions online. (Sari Frigård, Swedish Pharmaceutical Society)

It took some effort to get familiar with the process as it was a first for me. (Frank Jørgensen, Norwegian Association of Hospital Pharmacists)

Frustratingly sometimes, the hospital pharmacist is at times physically far from the patient or from other healthcare professionals, so through this process it was hoped that topics could be discussed more easily. A key question when evaluating the Summit is, did it work?

The views of patients and their involvement gives the process added credence and strength. (David Miller, The Guild of Healthcare Pharmacists, UK) 
Involving all partners and stakeholders empowers the EAHP Statements enormously. (Steffan Aman, ADKA-The German Society of Hospital Pharmacists)

It should have been easier to involve the other members of the national board and other national stakeholders in the process, e.g. the chief pharmacists of the hospital pharmacies. Hence I felt it challenging to fully convey the perspective of our members. (Frank Jørgensen, Norwegian Association of Hospital Pharmacists)

The process was a success because EAHP members, in addition to other stakeholders, felt that they were able to convey key messages on behalf of their associations, and the final statements mostly reflect their inputs during the process.

\section{THE EFFECT OF THE EAHP STATEMENTS FOR EAHP MEMBERS}

The statements now provide a consensus that can used by EAHP member associations to improve the practice of pharmacy in their country, and to encourage their members to strive for improved service delivery and discuss the statements with their governments.

\section{What will the effect be for an EAHP member association?}

It will be a very good tool to discuss and compare our standards and to use [them] in discussions with our stakeholders. The statements give us a common and clear framework with a common glossary so that we can understand each other easier. (Sari Frigard, The Section for Hospital Pharmacy at the Swedish Pharmaceutical Society)

It will hopefully provide a solid and legitimate background for our association to further pursue our common goals. (András Süle, Hungarian Society of Hospital Pharmacists)

The EAHP statements will strengthen the position of our national association when it comes to [the] development of hospital pharmacy agenda according to current priorities related to everyday practice in hospital pharmacies. (Nenad Miljkovic, The Pharmaceutical Association of Serbia, Hospital Pharmacy Section)

A positive effect, but it will be necessary to invest much energy and work for their implementation in practice. (Franci Tratar, Slovenian Pharmaceutical Society, Section of Slovenian Hospital Pharmacists)

We feel more confident to move forward in terms of our professional goals and future developments of hospital pharmacy in Estonia. (Marika Saar, Estonian Society of Hospital Pharmacists)

The statements could be a sort of framework for the activities in the association. (Magnus Munge, Swedish Pharmaceutical Society)

The statements will help us [with] the implementation of some processes in the hospital pharmacy. (Miroslav Kota, Croatian Pharmaceutical Society)

Not sure yet. The Association hopes to make use of them in an ongoing process of developing a new policy for medicines and medicines management on a national level. (Frank Jørgensen, Norwegian Association of Hospital Pharmacists)

We already have national statements and these can provide support. (David Miller, The Guild of Healthcare Pharmacists, UK)

Every EAHP statement itself will surely have an impact on creating the appropriate aforementioned tools according to the level of implementation in each hospital. (Nenad Miljkovic, The Pharmaceutical Association of Serbia, Hospital Pharmacy Section)
The statements will influence hospital pharmacy in our country. We have our paper about hospital pharmacy and these Statements will influence this. (Board Member of ADKA-The German Society of Hospital Pharmacists, Germany)

It depends on cooperation between hospital pharmacists and other healthcare professionals. (Marek Lžičař, Czech Association of Hospital Pharmacists)

\section{HELPING HOSPITAL PHARMACISTS IMPROVE THEIR PRACTICE}

To be helpful for hospital pharmacists, the statements need to reflect national practice and also suggest realistic improvements so that hospital pharmacists can engage with them. In my opinion the commitment of the profession, governments and stakeholders will be key to implementing the ambitious goals described in these statements. Do colleagues agree?

I think the statements will help in supporting the members in that they are on the right track. (Frank Jørgensen, Norwegian Association of Hospital Pharmacists)

It will provide me with a structure against which I will be able to measure the progression of my practice. (EAHP member)

Some statements will be quite challenging for our hospital pharmacies, especially those reflecting clinical pharmacy issues. But we are ready to move forward and hope that our European colleagues will help us to achieve our goals. (Marika Saar, Estonian Society of Hospital Pharmacists)

For some colleagues, the EAHP statements will definitely serve as a starting point to improve their practice, for others the statements will be the goal that they might have already achieved. (Nenad Miljkovic, The Pharmaceutical Association of Serbia, Hospital Pharmacy Section)

I think that the EAHP statements will help hospital pharmacists because they give us an [idea] about our skills and our mission. (Board Member of ADKA-The German Society of Hospital Pharmacists, Germany)

If implemented across Europe, they will improve patient care and that is their raison d'etre. (David Miller, The Guild of Healthcare Pharmacists, UK)

They could [improve hospital pharmacy], but in my opinion, this is highly dependent on the health policy of the state, willingness to change and available financial resources. (Franci Tratar, Slovenian Pharmaceutical Society, Section of Slovenian Hospital Pharmacists)

Yes, [the statements will improve hospital pharmacy] since the statements are clear and guides to even better practice. (Sari Frigård, The Section for Hospital Pharmacy at the Swedish Pharmaceutical Society)

Hopefully, it will start a new discussion and motivate hospital pharmacists. (Steffan Amann, ADKA-The German Society of Hospital Pharmacists)

\section{ACHIEVING THE STATEMENTS}

Achieving the statements may be easier for some areas of practice, or for some countries, but each EAHP member will have areas of priority for improvement. The delegates who were at the Summit provide insight and describe how the statements will be used for future implementation:

The effect will come later, when we understand our level of practice. It will be easier to benchmark with other countries to learn and improve. (Sari Frigård, The Section for Hospital Pharmacy, Swedish Pharmaceutical Society) 
Much of what was written is current practice. (David Miller, The Guild of Healthcare Pharmacists, UK)

[The statements will be achieved] only if they are widely recognized. (András Süle, Hungarian Society of Hospital Pharmacists)

It may support the political work of the national society of hospital pharmacists. (Steffan Amann, ADKA-The German Society of Hospital Pharmacists)

We will have tools for future activities. (Miroslav Kota, Croatian Pharmaceutical Society)

If they are able to implement them (most likely stepwise), it will signify a major leap in hospital pharmacy practice all over Europe. I have taken home two important messages: think strategic about implementation and think of the metrics. (Arnold G. Vulto, Dutch Association of Hospital Pharmacists)

I believe it provides a framework that can be referred to and adds strengths to the progression of our profession when campaigning for advances. (EAHP Member)

\section{CONCLUDING REMARKS}

Participating in the process was very motivating and the report about the EAHP Summit was given to our members just a few days after at the general assembly. (Steffan Amann, ADKA-The German Society of Hospital Pharmacists)

It was a very clever setup with very skilled top-notch moderators in each working group. These people were (a) knowledgeable on what we were working on, (b) focussed on the result and (c) experienced in guiding us how to get there. Thanks for this wonderful experience. (Arnold G. Vulto, Dutch Association of Hospital Pharmacists)

After reviewing these comments, it is clear that the EAHP membership is proud of the Statements and the work that has gone into their creation, and is now looking forward to the future. While not shirking the enormity of the task ahead of us, I realistically think that the statements have and will in the future "start the discussion and motivate hospital pharmacists" across Europe. A great outcome and one I am proud to be involved with.

Acknowledgements Thank you to all the EAHP members and the facilitation team who attended the Summit, providing both comments and the motivation required during the process to produce these excellent statements for the future of hospital pharmacy in Europe.

Competing interests None.

Provenance and peer review Commissioned; internally peer reviewed. 